Directing the scope of resuscitation towards the heart and brain. Resuscitation. 2006;70:44-51.

4. Beyersdorf F, Kirsh M, Buckberg GD, Allen BS. Warm glutamate/aspartate-enriched blood cardioplegic solution for perioperative sudden death. $J$ Thorac Cardiovasc Surg. 1992;104:1141-7.

5. Beyersdorf F, Acar C, Buckberg GD, Partington MT, Okamoto F, Allen BS, et al. Studies on prolonged regional ischemia. IV. Aggressive surgical treatment for intractable ventricular fibrillation after acute myocardial infarction. $J$ Thorac Cardiovasc Surg. 1989;98:557-66.

http://dx.doi.org/10.1016/ j.jtcvs.2014.07.025

\section{THE IMPORTANCE LIES ON THE PROCESS AND CARE DELIVERY OF RESUSCITATION IN PERIOPERATIVE CARDIAC SURGICAL CARE \\ Reply to the Editor:}

I read with interest the letter from Buckberg and colleagues, "Resuscitation in Cardiac Surgical Patients: Symptoms Versus Cause," written in response to the recent expert review of resuscitation practices in cardiac surgery by Gosev and associates ${ }^{1}$ and the accompanying commentary. ${ }^{2}$ The letter's authors report their experience treating a diverse subset of patients with perioperative sudden cardiac death by institution of cardiopulmonary bypass, insertion of left ventricular vent, aortic crossclamping, and delivery of controlled reperfusion with a substrate-enriched reperfusate. ${ }^{3}$ More importantly, they emphasize correction of the underlying etiology. This particular study involved 34 patients from 4 institutions, only 10 of whom were patients with sudden cardiac arrest occurring in the intensive care unit after cardiac surgery. All patients in this setting had sudden cardiac death occur after coronary artery bypass grafting. The controlled reperfusion technique with warm glutamate and aspartate-enriched blood cardioplegic solution was reported in 1992 by the same group, describing 14 patients with witnessed perioperative sudden cardiac arrest. ${ }^{4}$ Results were promising, with 11 patients being discharged from the hospital after receiving prolonged perioperative cardiopulmonary resuscitation. These 2 studies both describe an excellent survival and neurologic outcome, and both had patients with cardiac arrest that ranged from 20 to 150 minutes before institution of extracorporeal circulation. The letter authors then propose that this method be mentioned and urge the audience to be aware of this technique, specifically in the prolonged resuscitation cases that are rendered hopeless.

Although commendable, these results are difficult to reproduce and incorporate in a standard approach. Moreover, it is difficult to conclude that the improved neurologic outcome was due to the use of the controlled reperfusion technique, rather than excellent resuscitation technique before the institution of cardiopulmonary bypass. The practice of cardiac surgery is growing more diverse than ever before, with more surgeries performed with minimally invasive or percutaneous approaches; development of multidisciplinary teams, such as the concept of the "heart team"; and the addition of more options for mechanical support. A significant part of the success of implementation of resuscitation practices, such as advanced cardiac life support, is the use of reproducible algorithms and predictable actions with clear roles and responsibilities of the different components of the care team. The major changes of advanced cardiac life support during the last 2 decades have been the adoption of simpler algorithms that enable clear goals without intricate complexities and the development of appropriate training programs with specific intervals. The intent of the expert review and commentary on resuscitation practices in cardiac surgery published last year in the Journal ${ }^{1,2}$ was to reinforce the importance of the process and standardization of resuscitation in this highly complex set of patients with a great window of opportunity for recovery as well as a call to create a standard from which post-cardiac surgery resuscitation can evolve.

The focus on etiology is of key importance during every event requiring resuscitation. With the diverse life-threatening problems that face the modern cardiac surgical patient who develops cardiac arrest, there is an urgent need to establish a standard approach with emphasis on maintenance of perfusion and defining the appropriate time for resternotomy and extracorporeal support. Because of the promising results of the described technique, it would be advisable to reproduce these findings in a broader cardiac surgical population with an emphasis in postoperative care.

Juan N. Pulido, MD

Divisions of Cardiovascular Anesthesia and Critical Care Medicine Department of Anesthesiology Mayo Clinic Rochester, Minn

\section{References}

1. Gosev I, Nikolic I, Aranki S. Resuscitation practices in cardiac surgery. J Thorac Cardiovasc Surg. 2014;148:1152-6.

2. Pulido JN. Unique aspects of resuscitation practices in postoperative cardiac surgical care: a call to action. J Thorac Cardiovasc Surg. 2014;148:1156-7.

3. Athanasuleas CL, Buckberg GD, Allen BS, Beyersdorf F, Kirsh MM. Sudden cardiac death: Directing the scope of resuscitation towards the heart and brain. Resuscitation. 2006;70:44-51.

4. Beyersdorf F, Kirsh M, Buckberg GD, Allen BS Warm glutamate/aspartate-enriched blood cardioplegic solution for perioperative sudden death. $J$ Thorac Cardiovasc Surg. 1992;104:1141-7.

http://dx.doi.org/10.1016/ j.jtcvs.2015.01.047

\section{DO EMERGENT AORTIC DISSECTION OPERATIONS INCREASE POSTOPERATIVE NEUROLOGIC COMPLICATIONS? \\ To the Editor:}

We congratulate Shi and colleagues for their report. Although it has been reported that some of the patients in the study had acute aortic dissection, 